\title{
The Key Role of Sulfation and Branching on Fucoidan Antitumor Activity
}

\author{
Catarina Oliveira, Andreia S. Ferreira, Ramon Novoa-Carballal, \\ Cláudia Nunes, Iva Pashkuleva, Nuno M. Neves, Manuel A. Coimbra, \\ Rui L. Reis, Albino Martins, Tiago H. Silva*
}

There is an urgent need for antitumor bioactive agents with minimal or no side effects over normal adjacent cells. Fucoidan is a marine-origin polymer with known antitumor activity. However, there are still some concerns about its application due to the inconsistent experimental results, specifically its toxicity over normal cells and the mechanism behind its action. Herein, three fucoidan extracts (FEs) have been tested over normal and breast cancer cell lines. From cytotoxicity results, only one of the extracts shows selective antitumor behavior (at $0.2 \mathrm{mg} \mathrm{mL}^{-1}$ ), despite similarities in sulfation degree and carbohydrates composition. Although the three FEs present different molecular weights, depolymerization of selected samples discarded $M_{\mathrm{w}}$ as the key factor in the antitumor activity. Significant differences in sulfates position and branching are observed, presenting FE 2 the higher branching degree. Based on all these experimental data, it is believed that these last two properties are the ones that influence the cytotoxic effects of fucoidan extracts.

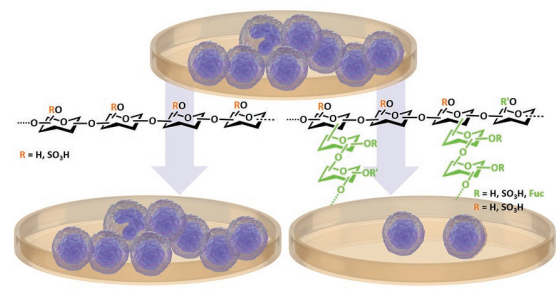

C. Oliveira, Dr. R. Novoa-Carballal, Dr. I. Pashkuleva,

Prof. N. M. Neves, Prof. R. L. Reis, Dr. A. Martins, Dr. T. H. Silva 3B's Research Group-Biomaterials

Biodegradables and Biomimetics

University of Minho

Headquarters of the European Institute of Excellence

on Tissue Engineering and Regenerative Medicine

AvePark, Parque de Ciência e Tecnologia

4805-017 Barco, Guimarães, Portugal

E-mail: tiago.silva@dep.uminho.pt

C. Oliveira, Dr. R. Novoa-Carballal, Dr. I. Pashkuleva,

Prof. N. M. Neves, Prof. R. L. Reis, Dr. A. Martins, Dr. T. H. Silva

ICVS/3B's

PT Government Associate Laboratory

Braga/Guimarães, Portugal

A. S. Ferreira, Dr. C. Nunes, Prof. M. A. Coimbra

QOPNA, Department of Chemistry

University of Aveiro

Campus de Santiago 3810-193, Aveiro, Portugal

Dr. C. Nunes

CICECO, Department of Chemistry

University of Aveiro

Campus de Santiago 3810-193, Aveiro, Portugal

\section{Introduction}

Cancer can have various origin-factors, being characterized by uncontrolled cell growth and spread. ${ }^{[1]}$ Cancer therapeutics aim to increase the survival time and the qualityof-life of the patients. The goal of cancer treatment is the extinction of tumor cells, ideally with minimal damage to healthy tissues. The toxic effects over normal cells often limit the current chemotherapeutic agents used in cancer treatments, which conduct to reduced dosage and, consequently, efficacy of the treatment. ${ }^{[2,3]}$

Breast cancer is the second most frequent diagnosed cancer and the first among females. ${ }^{[4]}$ If breast cancer is detected in an early stage, there is a possibility to be treated and removed surgically. However, the treatment of the advanced stage breast cancer is often followed by reoccurrence and can become fatal, even when chemotherapeutic agents are administered. There are several factors such as tumors heterogeneity, drug resistance, side effects, and toxicity to healthy tissues, that diminish the efficacy and usefulness of this 
treatment. ${ }^{[5,6]}$ Therefore, there is a strong interest in developing better-tolerated anticancer agents and treatment modalities. ${ }^{[7]}$

Because of the side effects of many current treatments, the use of natural substances with low toxicity is of great interest. ${ }^{[8]}$ Natural-derived polymers are of special interest due to their biological and chemical similarities to natural tissues composition. Marine organism are valuable sources of materials with intriguing properties and characteristics. ${ }^{[9]}$ Among marine-origin materials, fucoidan is a polysaccharide that consists of sulfated fucose residues and is possible to be extracted from brown seaweeds of different species such as Fucus vesiculosus, Laminaria japonica, and Undaria pinnatifida. ${ }^{[10-12]}$ Fucoidan has been reported to have various biological activities including antibacteria, antioxidant, antiviral, and antitumor. ${ }^{[13,14]}$

Fucoidan antitumor behavior has been demonstrated in vitro and in vivo for different type of cancers such as breast, lung, prostate, colon, and melanoma. ${ }^{[7,15-18]}$ It retards tumor development, eradicating tumor cells by targeting key apoptotic molecules. Furthermore, the synergistic effect of fucoidan with current anticancer agents has also been reported. ${ }^{[8,19]}$ Despite the promising results about its anticancer effects, the fucoidan mechanism of action is not clearly understood and thus, fucoidan has not yet been developed as a regulated therapeutic agent. ${ }^{[20,21]}$ The main barriers to its utilization in clinic are: (i) its toxicity to normal cells, and (ii) the variable and contradictory results in fucoidan usage. ${ }^{[8,22]}$ In addition, there are a huge variety of algae fucoidan sources, which implies various extraction and purification methods that may influence fucoidan's intrinsic properties and its bioactivity such as molecular weight, carbohydrates composition, and sulfation. Molecular weight has been reported as one of the main factors influencing fucoidan antitumor behavior. From previously reported works, lower molecular weight fucoidan presents higher antitumor effects whereas higher sulfation degree has been related with enhanced bioactivity responses. ${ }^{[23,24]}$ However, most studies analyzing antitumor activity did not characterize in detail the composition of the used fucoidan and this is probably the cause of some contradictory findings. ${ }^{[10,14,25]}$

An effective cancer therapeutic strategy is characterized by the ability to eliminate tumors without damaging healthy tissues. Due to the different properties affecting fucoidan bioactivity, there is the need to evaluate the antitumor effects of a certain extract and characterize which feature(s) is (are) playing the major role. For that purpose, herein, three different extracts from the same species (i.e., F. vesiculosus) were tested with human breast cancer cells, and normal endothelial and fibroblastic cells. From these biological data we were able to observe three completely different bioactive responses and, in that sense, we decided to carry out structure-activity relationship studies.

\section{Results}

\subsection{Cytotoxicity of Fucoidan Extracts}

2.1.1. Fucoidan Extract 1 (FE 1) Does Not Present Toxic Effects over Cancer Cells and Shows Toxicity for Normal Cells

FE 1 presents cytostatic effects at day 2 and day 3 for MDAMB-231 cell line as demonstrated by the inhibited cells growth when compared to the control and lower concentrations (Figure 1A). Regarding MCF-7 cell line, fucoidan presents toxic effects only at day 3 and at concentration of $5 \mathrm{mg} \mathrm{mL}^{-1}$ (Figure 1B). Cytotoxic assays for the normal cells showed cytotoxic effect at day 2 for concentrations above $2 \mathrm{mg} \mathrm{mL}^{-1}$ (Figure 1C,D).

2.1.2. FE2 Induces Cancer Cells Death but Does Not Affect the Viability of Normal Cells at $0.2 \mathrm{mg} \mathrm{mL}^{-1}$

We began to test FE2 at the same concentrations as the FE1. However, a significant effect of fucoidan over the breast cancer cell lines was revealed at low concentrations: at day 2 and at concentration of $0.2 \mathrm{mg} \mathrm{mL}^{-1}$, the fucoidan induces cell death for both MDA-MB-231 and MCF-7 cell lines (Figure 2A,B). This effect become more pronounced at higher fucoidan concentrations. The two types of normal cells show distinct behavior: cytostatic effect for the endothelial cells was observed at day 2 and at concentration of $0.5 \mathrm{mg} \mathrm{mL}^{-1}$ (Figure 2C), while, for fibroblastic cells this effect was seen above concentration of $0.3 \mathrm{mg} \mathrm{mL}-1$ (Figure 2D).

These results demonstrated that FE2 induces apoptosis for the two types of tumor cells above $0.2 \mathrm{mg} \mathrm{mL}^{-1}$ and maintains the viability of normal endothelial and fibroblastic cells at the same concentration.

\subsubsection{FE3 Is Toxic to Both Cancer and Normal Cells}

Similar to FE2, FE3 induces cancer cells death at day 1 for concentrations above $0.2 \mathrm{mg} \mathrm{mL}^{-1}$ (Figure 3A,B). However, fucoidan extract 3 (FE 3) affects also the normal cells at this concentration and thus, its effect differs from FE2. Stronger cytostatic effect was observed for endothelial cells (Figure 3C): significantly diminished proliferation was measured for the cells at $0.1 \mathrm{mg} \mathrm{mL}^{-1}$ concentration and significant cytotoxic effect is observed above concentration of $0.3 \mathrm{mg} \mathrm{mL}$. Concerning the fibroblastic cells, fucoidan has severe consequences over this cell type and the cytotoxic effect is observed for concentration above $0.2 \mathrm{mg} \mathrm{mL}^{-1}$ (Figure 3D). 

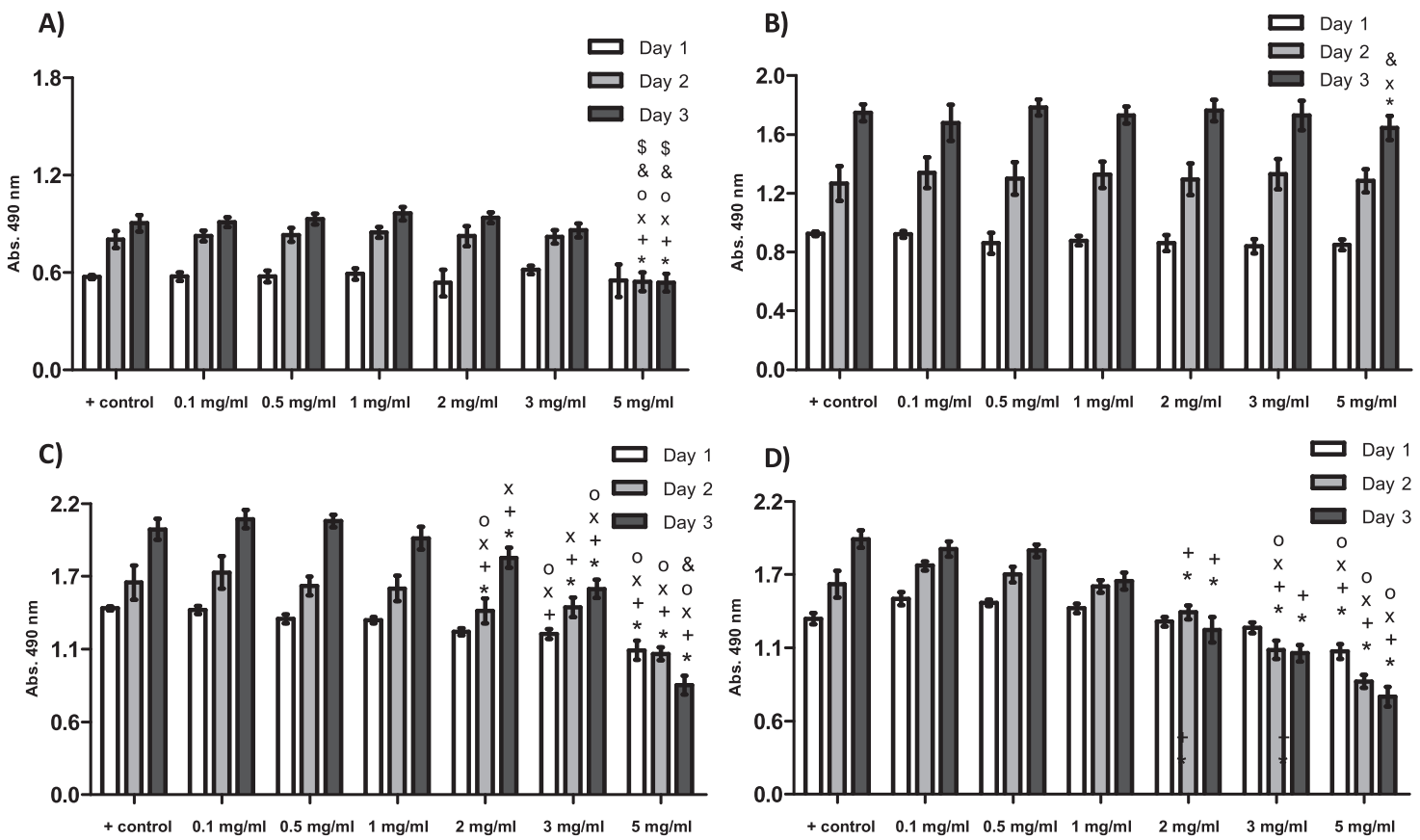

Figure 1. Cytotoxicity of FE 1, at different concentrations and time-points (1, 2, and 3 days), over human cell lines A) MDA-MB-231, B) MCF-7, C) HPMEC-ST1.6R, and D) MRC-5. Data were considered statistically different if $p<0.05 .{ }^{*}$ indicates significant differences when compared to + control; ; when compared to $0.1 \mathrm{mg} \mathrm{mL}^{-1}$; ${ }^{x}$, when compared to $0.5 \mathrm{mg} \mathrm{mL}^{-1}$; ${ }^{\circ}$, when compared to $1 \mathrm{mg} \mathrm{mL}^{-1}$; \&, when compared to $2 \mathrm{mg} \mathrm{mL}^{-1}$, and $\$$, when compared to $3 \mathrm{mg} \mathrm{mL}^{-1}$.
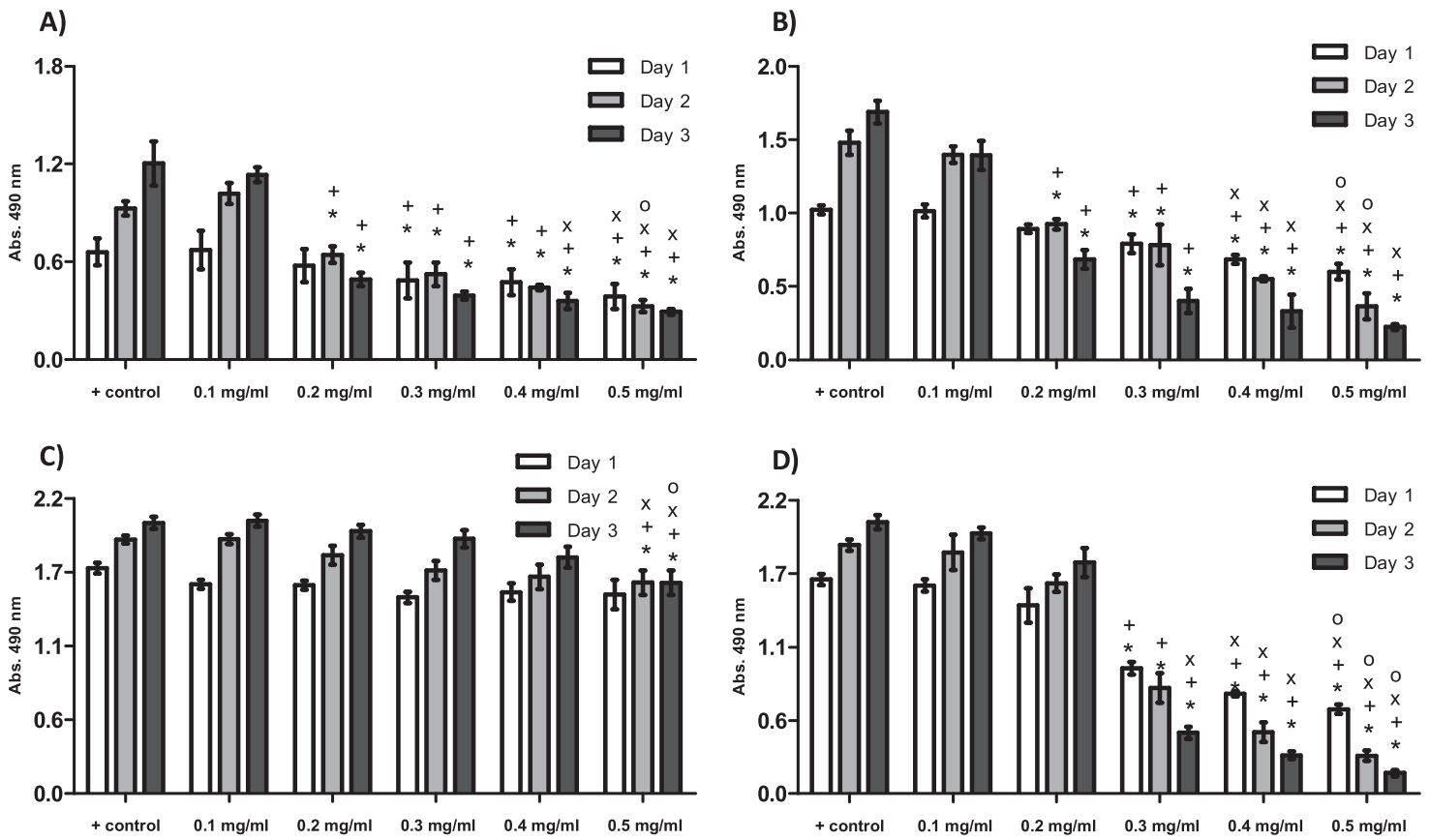

Figure 2. Cytotoxicity of FE 2, at different concentrations and time-points (1, 2, and 3 days), over human cell lines A) MDA-MB-231, B) MCF-7, C) HPMEC-ST1.6R, and D) MRC-5. Data were considered statistically different if $p<0.05 .{ }^{*}$ indicates significant differences when compared to + control; ${ }^{+}$, when compared to $0.1 \mathrm{mg} \mathrm{mL}^{-1}$; ${ }^{\mathrm{x}}$, when compared to $0.2 \mathrm{mg} \mathrm{mL}^{-1}$; ${ }^{\circ}$, when compared to $0.3 \mathrm{mg} \mathrm{mL}^{-1}$, and ${ }^{\text {\& }}$, when compared to $0.4 \mathrm{mg} \mathrm{mL}^{-1}$. 
A)

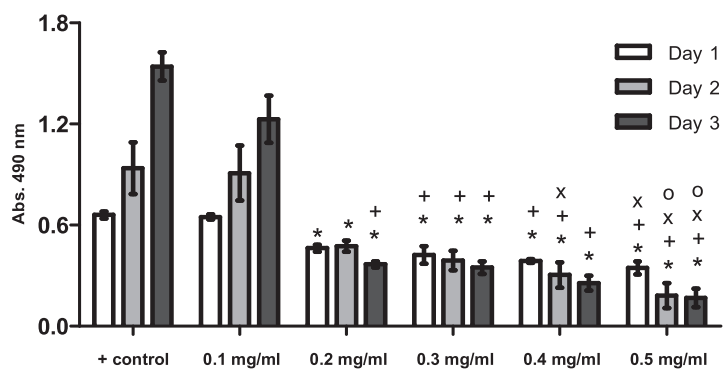

C)

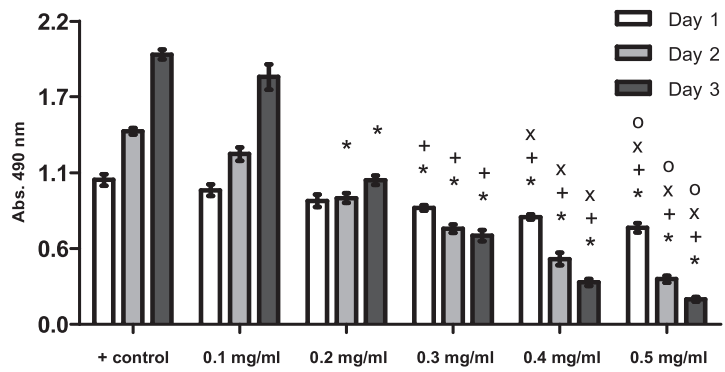

B)

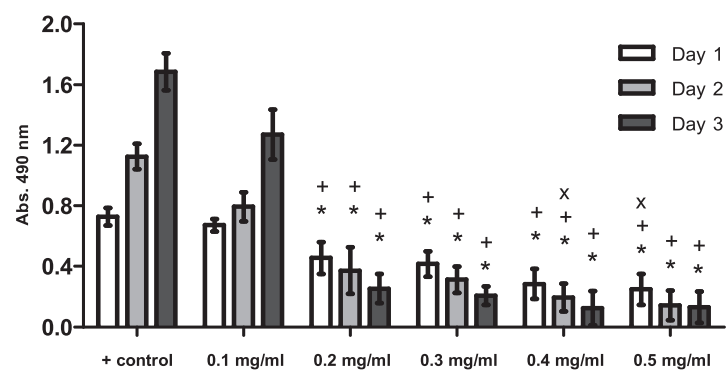

D)

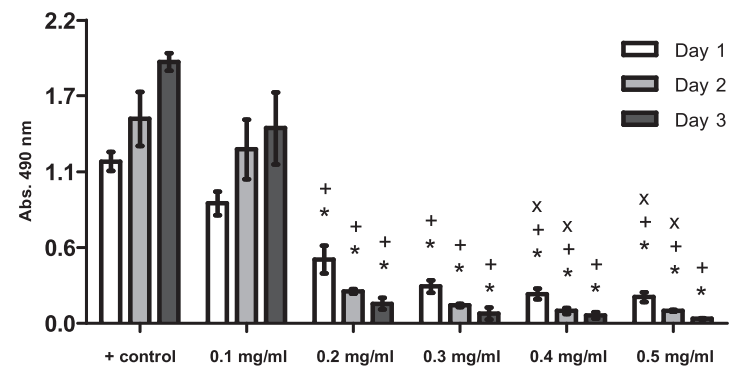

Figure 3. Cytotoxicity of FE 3 , at different concentrations and time-points (1, 2, and 3 days), over human cell lines A) MDA-MB-231, B) MCF-7, C) HPMEC-ST1.6R, and D) MRC-5. Data were considered statistically different if $p<0.05 .{ }^{*}$ indicates significant differences when compared to + control; ${ }^{+}$, when compared to $0.1 \mathrm{mg} \mathrm{mL}^{-1}$; ${ }^{\mathrm{x}}$, when compared to $0.2 \mathrm{mg} \mathrm{mL}^{-1}$; ${ }^{\circ}$, when compared to $0.3 \mathrm{mg} \mathrm{mL}^{-1}$, and \&, when compared to $0.4 \mathrm{mg} \mathrm{mL}^{-1}$.

\subsection{Physicochemical Characterization of the Different Fucoidan Extracts}

\subsubsection{Molecular Weight}

The gel permeation chromatography (GPC) analysis showed that the three extracts have significantly different molecular weight. A smallest retention volume (longer chain) was determined for FE 1 (Figure 4A,B). The molecular weight of FE 1 is two times higher when compared with FE 3 . All the three extracts have a very similar $M_{\mathrm{w}} / M_{\mathrm{n}}$ (polydispersity).

5-([4,6-Dichlorotriazin-2-yl]amino)fluorescein hydrochloride (DTAF)-Labeled Fucoidans' Cellular Internalization: An internalization assay was performed to assess if cancer cells were able to internalize the FE based on its molecular weight. In that sense fucoidan extract 2 (FE 2) (the one with selective bioactivity) was compared with
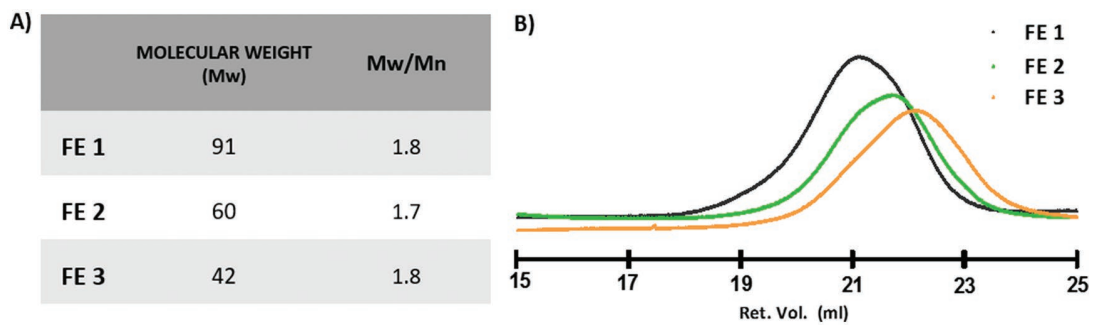

Figure 4. A) Molecular weight $\left(M_{\mathrm{w}}\right)$ and $M_{\mathrm{w}} / M_{\mathrm{n}}$ of FE 1, FE 2, and FE 3 measured by GPC, B) molecular weight chromatograms.
FE 1 (no bioactive activity and higher molecular weight). No green labeling is observed for the positive controls and DTAF (Figure 5) showing that DTAF alone is not internalized by breast cancer and endothelial cells. Endothelial cells cultured with labeled FE 1 and FE 2 do not present any green fluorescence, i.e., DTAF-labeled fucoidan was not internalized by these cells. On the other hand, breast cancer cells internalized the labeled fucoidan: green staining localized near to the nucleus is visible in Figure 5 for both FE 1 and FE 2.

FE 1 Hydrolysis: The above results (Figures 4 and 5) did not lead straightforward to any conclusions about the significance of molecular weights on fucoidans bioactivity. However, since many authors related the $M_{\mathrm{w}}$ with the antitumor activity we performed further analysis about its influence. The FE 1 (the one with higher molecular weight) was hydrolyzed by an acidic reaction in boiling water to lower molecular weight polymer and we further analyzed it. We obtained a polymer with molecular weight of $40 \mathrm{kDa}$ (Figure 6A). This molecular weight is similar to the one of FE 3 that has toxic effect over both cancer and normal cells. The toxicity of this new polymer (FE 1*) was evaluated with breast cancer and endothelial cells and demonstrated no significant differences as compared with the initial FE1 (Figure 6C,D vs Figure 1B,C). 

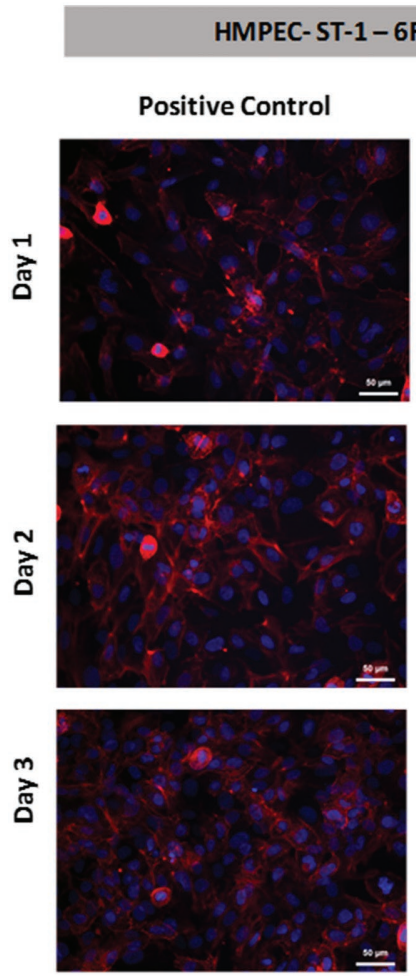

DTAF-labeled FE 1
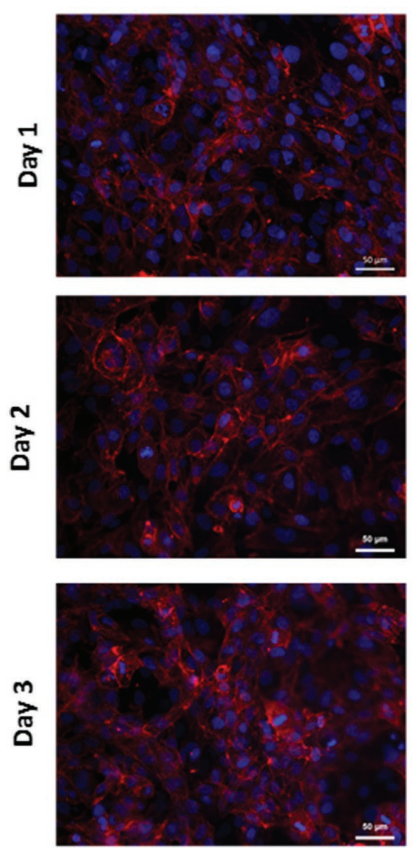

DTAF-labeled FE 2
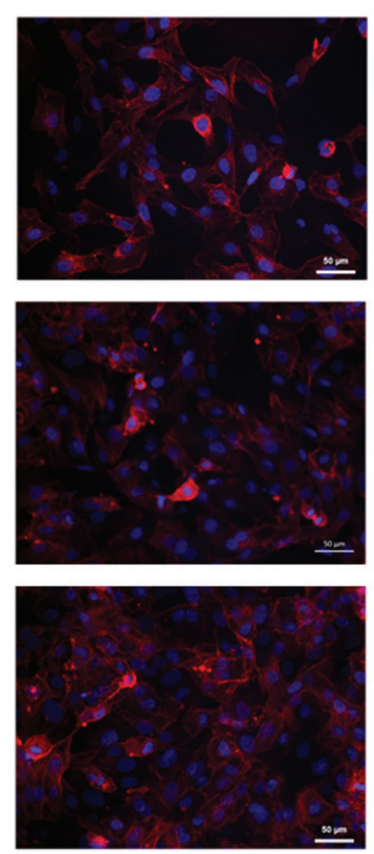

\section{MCF-7 Breast cancer cells}
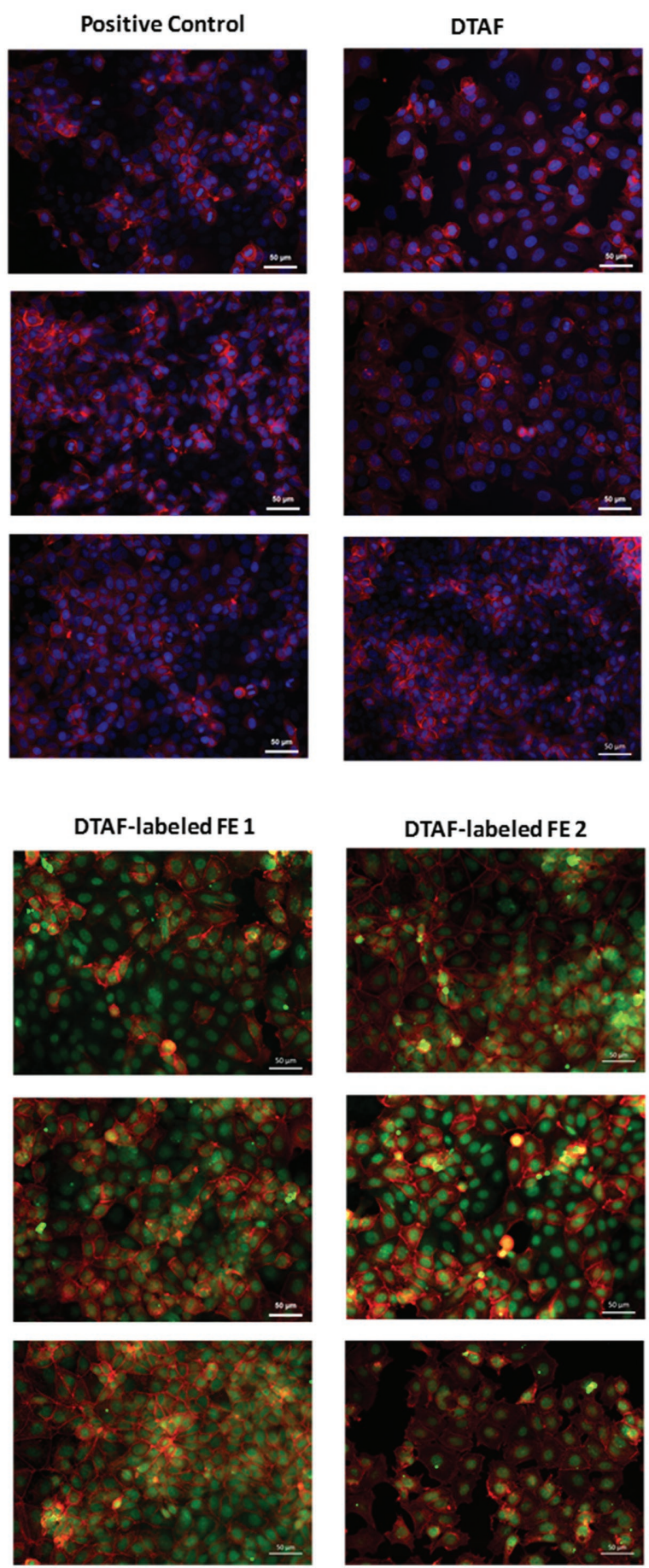

Figure 5. Internalization of DTAF-labeled FE 1 and FE 2 by HPMEC-ST-1-6R and MCF-7 cell lines. In MCF-7 cultures, the nucleus staining by DAPI was omitted in face of the colocalization of internalized DATF-labeled fucoidans.

\subsubsection{Carbohydrates Composition}

The obtained results for the monomeric composition of the analyzed sulfated-polysaccharides (Table 1) showed that the predominant sugar was the fucose $(71.2 \%-79.1 \% \mathrm{~mol})$, as expected. The following sugars are the uronic acids $(9.8 \%-15.3 \% \mathrm{~mol})$, xylose $(3.9 \%-8 \% \mathrm{~mol})$, galactose $(3.5 \%-5.5 \% \mathrm{~mol})$, and minor amounts of mannose and glucose. It seemed that there are not much differences between the analyzed fucoidan extracts. When comparing 
A)

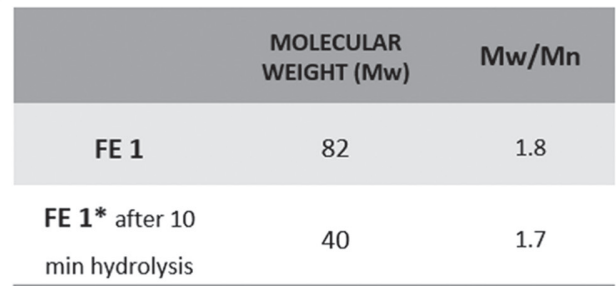

B)

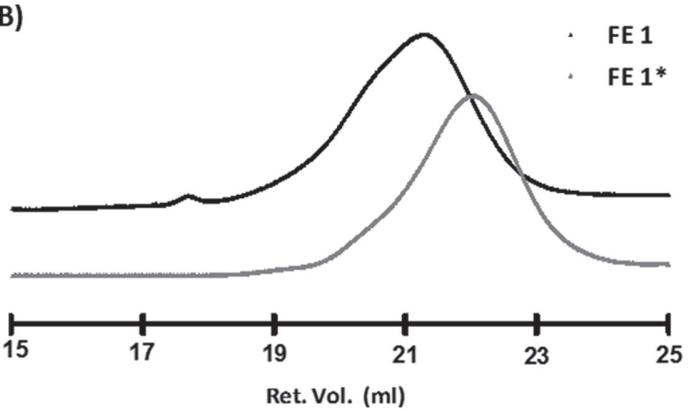

c)

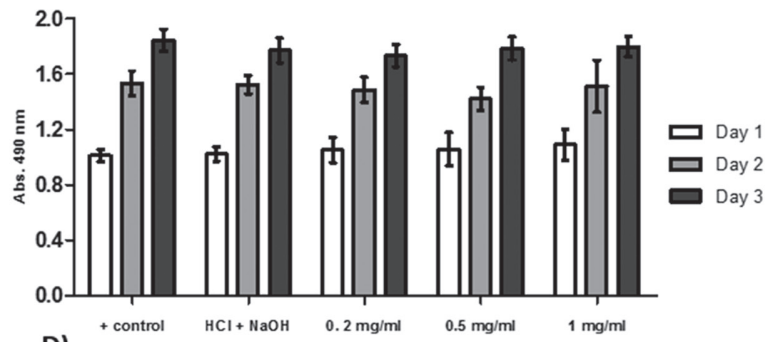

D)

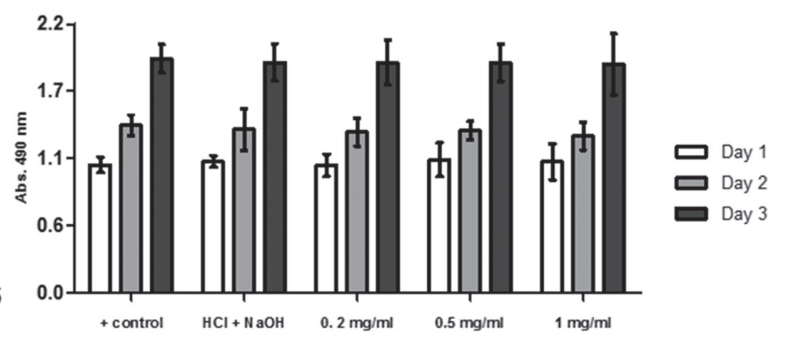

Figure 6. A) Molecular weight $\left(M_{w}\right)$ and $M_{w} / M_{n}$ measured by GPC, B) molecular weight chromatogram. Cytotoxicity of FE $1^{*}$ over C) MCF-7 and D) HPMEC-ST-1.6R cell lines. No statistical significant differences were observed.

one of the previous referred extracts with FE 1 (no toxicity over cancer cells) we often find comparable values, with at least one of the extracts (FE 2 and FE 3). The total sugar mass per extract mass is also very similar for the three extracts. Having a closer look into the quantification of neutral sugars and uronic acids, and having in mind that FE 2 and FE 3 are the ones that present toxicity to cancer cells, it is not possible to find any correlation between these sugar components and the anticancer activity.

\subsubsection{NMR Spectroscopy}

The differences in the biological activity observed in FE seems to be unrelated to the $M_{\mathrm{w}}$ and sugars composition therefore we decided to analyze in detail the sulfation and branching of the samples. The fastest way to compare the three extracts and obtain a general idea of the differences in composition is ${ }^{1} \mathrm{H}$ NMR. The ${ }^{1} \mathrm{H}$ NMR of the three samples at $400 \mathrm{MHz}$ is included in Figure 7.

The spectra correspond to the previously described for fucoidan samples with the isolated regions of the fucose methyl protons (H6, 1-1.5 ppm), acetyl protons (at $2.2 \mathrm{ppm}$ with a small proportion 0.5 to 1 acetyl groups per every 10 fucose residues) and anomeric (5.0-5.5 ppm) and a highly overlapped region corresponding to all other signals in the fucose ${ }^{1} \mathrm{H} \mathrm{NMR}^{[26]}$ The strong overlap hampers a very detailed information but the three extracts show enough differences to expect considerable different composition. Especially interesting was difference the region around 3.9-4.3 ppm that contains signals attributed to branched fucose. ${ }^{[27]}$ In light of these results a detailed study of sulfation position and branching was performed by methylation analysis.

\subsubsection{Sulfation Degree and Methylation Analysis}

Sulfation is another key factor in fucoidan bioactivity: higher sulfation degree is often associated with greater bioactivity. ${ }^{[28]}$ Quantification results demonstrate that the studied extracts have a very similar total percentage of sulfates, which varies between $28.0 \%$ and $29.3 \%$. The analysis of partially methylated alditol acetates before (native) and after desulfation (desulfated) of fucoidans allow to know the substitution of sugar residues, corresponding to

Table 1. Carbohydrates composition of the three fucoidan extracts.

\% total sugar mass/ extract mass
$\%$ molar of neutral sugars

Fucose

FE1

FE2

$52.5 \pm 2.5$

$73.1 \pm 0.4$

Xylose

Mannose

Galactose

$1.3 \pm 0.2$

$3.5 \pm 0.3$

Glucose

FE3

$52.2 \pm 1.9$

$79.1 \pm 0.6$

$3.9 \pm 0.0$

$0.8 \pm 0.0$

$5.5 \pm 0.1$

$0.8 \pm 0.0$

$5.4 \pm 0.0$

$1.3 \pm 0.9$
$71.2 \pm 0.5$

$5.3 \pm 0.1$

$\%$ molar of uronic acids 


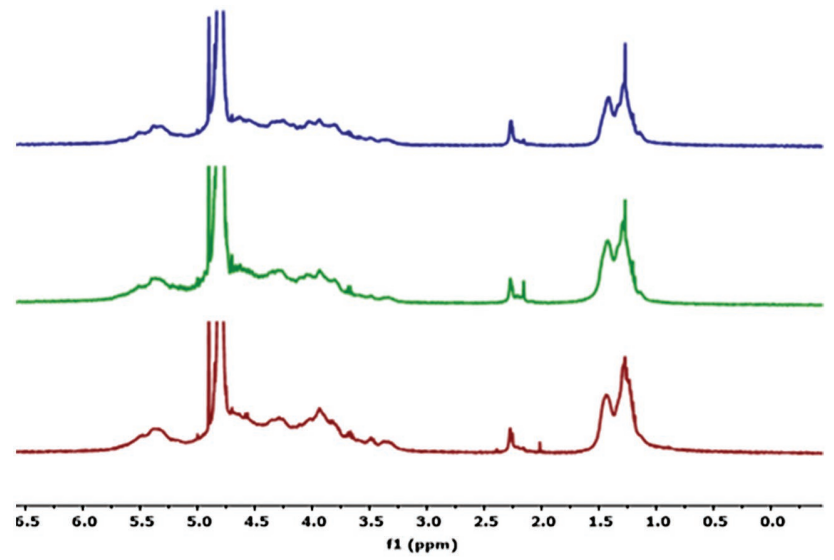

Figure 7. $1 \mathrm{H}$ NMR spectra $\left(400 \mathrm{MHz}, \mathrm{D}_{2} \mathrm{O}, 25^{\circ} \mathrm{C}\right)$ of the fucoidan extracts: FE1 bottom, FE 2 middle, and FE 3 top.

branching points and the substitution by sulfate esters. When a position is acetylated in the native polysaccharide and become methylated after desulfation, it is indication that this position contains a sulfate residue. However, when a position is acetylated even after desulfation of the polysaccharide, it can be inferred that it is a branching point. The results are shown in Table 2.

In native fucoidan extracts, 2,3,4-Fuc was the major residue for the three extracts, followed by 2,4- and 2,3-Fuc (coeluated peaks) residues, indicating a high percentage of substituted fucose. After desulfation it was observed the decrease of these specific residues $(75 \%-80 \%$ for
2,3,4-Fuc and $46 \%-61 \%$ for 2,4-Fuc + 2,3-Fuc), meaning that part of the substituents was sulfate esters that were removed with the desulfation procedure. An increase mainly of the 4-Fuc and 3-Fuc residues after desulfation allowed to infer that the fucoidan backbone was constituted by these linkages, which is in accordance with literature, reporting that $F$. vesiculosus fucoidan main chain is composed of alternating 4-O and 3-O fucose linkages. ${ }^{[29,30]}$ These results allowed also to conclude that sulfate esters were mainly linked in 2-O fucose. However, the observation of the 2-O linkage in the desulfated sample shows that this linkage should be also a characteristic of the fucoidan structure. The increase of 3,4-Fuc residues after desulfation, as well as the maintenance of about $10 \%$ of 2,3,4-Fuc, 2,4-Fuc, and 2,3-Fuc branched residues, corroborate the presence of a branched fucoidan structure mainly in 3-O or 4-O positions. As the sum of all branched residues is equal to the sum of terminal residues of Fuc, $\mathrm{Xyl}$, and UA (GlcA and GalA), it can be inferred that the fucoidan had a polymeric nature (no extra Fuc terminal residues), containing fucose, xylose, and uronic acids as side chains terminal residues.

The branching degree (sum of branched Fuc/(total Fuc minus the terminal Fuc), indicates the frequency (\%) of side chain residues present in the backbone. Therefore, this structural feature of the polysaccharides was determined for FE 1, FE 2, and FE 3 and allowed to show that FE 2 was more branched (83.4\%) than FE $1(67.5 \%)$ or FE 3 (60.4\%) (Table 2).

Table 2. Sulfation degree (\%), glycosidic-substitution composition (\%) of fucoidan samples in fractions FE 1, FE 2, and FE 3, before and after desulfation.

\begin{tabular}{|c|c|c|c|c|c|c|}
\hline Sulfation degree (\% sulfate mass/extract mass) & \multicolumn{2}{|r|}{ FE 1} & \multicolumn{2}{|r|}{ FE 2} & \multicolumn{2}{|r|}{ FE 3} \\
\hline \multirow[t]{2}{*}{ Sugar residues and substitution positions } & \multicolumn{2}{|c|}{$28.0 \pm 1.4$} & \multicolumn{2}{|c|}{$29.3 \pm 2.8$} & \multicolumn{2}{|c|}{$28.6 \pm 1.9$} \\
\hline & Native & $\overline{\text { Desulfated }}$ & Native & Desulfated & Native & Desulfated \\
\hline t-Fuc & 5.5 & 14.2 & 4.2 & 13.1 & 4.7 & 13.4 \\
\hline 4-Fuc & 0.9 & 10.6 & 1.9 & 7.6 & 1.5 & 11.0 \\
\hline 3-Fuc & 1.5 & 9.3 & 1.2 & 7.3 & 1.5 & 13.6 \\
\hline 2-Fuc & 5.1 & 8.8 & 3.9 & 5.2 & 4.1 & 5.7 \\
\hline 3,4-Fuc & 3.9 & 12.3 & 7.3 & 11.2 & 5.8 & 9.2 \\
\hline 2,4-Fuc + 2,3-Fuc & 19.1 & 10.3 & 24.8 & 10.6 & 27.6 & 10.7 \\
\hline 2,3,4-Fuc & 42.8 & 9.1 & 42.9 & 11.3 & 34.8 & 6.8 \\
\hline Total Fuc & 78.8 & 74.6 & 86.3 & 66.3 & 79.9 & 70.4 \\
\hline t-Xyl & 6.8 & 9.1 & 3.3 & 7.7 & 4.4 & 8.2 \\
\hline $\mathrm{t}-\mathrm{GlcA}+\mathrm{t}-\mathrm{GalA}$ & 14.5 & 16.3 & 10.4 & 26.0 & 15.6 & 21.4 \\
\hline Branching degree [\%] & \multicolumn{2}{|r|}{67.5} & \multicolumn{2}{|r|}{83.4} & \multicolumn{2}{|r|}{58.9} \\
\hline 4-O linkage & \multicolumn{2}{|r|}{30.5} & \multicolumn{2}{|c|}{27.4} & \multicolumn{2}{|c|}{38.5} \\
\hline 3-O linkage & \multicolumn{2}{|r|}{34.9} & \multicolumn{2}{|r|}{29.4} & \multicolumn{2}{|r|}{27.7} \\
\hline 2-O linkage & \multicolumn{2}{|r|}{55.6} & \multicolumn{2}{|r|}{50.9} & \multicolumn{2}{|c|}{60.3} \\
\hline
\end{tabular}


The percentage of sulfate present in each fucose position (4-,3-, and 2-O linkage) was determined based on the increase of each fucose linkage after desulfation in relation to the native fucoidan (Table 2). The major percentage of sulfate esters was present in the 2-O-Fuc for all extracts (51\%-60\%), which is in agreement with literature. ${ }^{[29,30]}$ In addition, it is also possible to observe the presence of sulfates in $3-0$ position $(28 \%-35 \%)$ and $4-O$ position ( $27 \%-36 \%)$. The FE 2 showed the presence of fewer sulfate esters in 4-O and 2-O positions when compared with the other extracts, in opposite to FE 3 that had a higher percentage of sulfates in 4-O and 2-O positions. FE 1 had a higher content of sulfate in 3-O position.

\section{Discussion}

Fucoidan has been reported to inhibit the growth of cancer cells, having a great interest in the development of new cancer therapies. ${ }^{[24]}$ When considering a cancer therapy, the ultimate goal is to affect cancer cells without damaging the surrounding healthy environment, having non or minimal side-effects. ${ }^{[31]}$ The tumor microenvironment comprises not only the cancer cells but also the noncancerous cells which includes endothelial cells, fibroblasts, and circulating immune cells. ${ }^{[32,33]}$ For this reason, it is of utmost importance to test whether fucoidan can only damage the tumor cells and not the healthy surrounding tissues. The three fucoidan extracts were tested with endothelial, fibroblastic and breast cancer cells. When designing a blood administered drug, there is a need to assure that its circulation will not affect the blood vessels. Therefore, we tested the cytotoxicity of fucoidan over human endothelial cells (HPMEC-ST-1.6R cell line). The healthy tissue around the tumor should not be affected when the drug enters into the interstitial fluid. Therefore, fucoidan should not affect this type of cells as well, herein represented by human fibroblasts (MRC-5 cell line). Breast cancer is one of the most frequent cancers and, as many other types of cancer, presents heterogeneous behavior. We used two different breast cancer cells lines to depict this tumor heterogeneity. MCF-7 cell line is an ideal cell model to study hormone responsive tumors since it is estrogen receptor (ER)-positive cells and forms tumors in the presence of estrogen. ${ }^{[34,35]}$ On the other hand, MDA-MB231 cell line is ER-negative and have been shown to be tumorigenic. $^{\text {[34] }}$

As previously stated, the desired effect of a cancer therapeutic strategy is that fucoidan has toxicity over cancer cell and no or diminished effects over noncancer cells. Some publications only show the effects of fucoidan over cancer cells. ${ }^{[19,36]}$ However, this can lead to some misinterpretation of fucoidans' antitumor activity, since it could also have toxic effects over normal cells. In the present study, we denoted that not all fucoidan extracts present this desired behavior. Specifically, FE 1, despite the wide range of concentrations, showed toxicity to normal cells at lower concentrations than cancer cells, resulting in an extract without antitumor features and not suitable for cancer therapies. On the other hand, both FE 2 and FE 3 presented toxicity to cancer cells, although FE 3 also presented toxicity to normal fibroblast cells at the same concentrations. Therefore, FE 3 has to be used with extreme careful and in a more target and precise way to try to affect only the cancer cells and diminished the toxic effects over noncancer cells, by not affecting the surrounding environment. ${ }^{[37]}$ The FE 2 is the one with the desired antitumor behavior, since it showed toxicity effects over cancer cells at $0.2 \mathrm{mg} \mathrm{mL}^{-1}$ and, at this concentration, neither endothelial nor fibroblastic cells were affected. From this first group of results, we conclude that not all fucoidans present desirable features, leading to different toxic profiles when in contact with the same cells.

After this biological screening, the next step was focused on the physicochemical characterization of the three extracts, trying to understand which feature(s) play(s) a pivotal role in this antitumor behavior. As previously reported, the physicochemical factors that may influence fucoidan bioactivity are the molecular weight, monosaccharide composition, sulfates degree, and sulfates position. Nevertheless, despite not being directly related with fucoidan intrinsic structure the source and extraction method have also been described to influence its bioactive behavior. ${ }^{[10,14,28,38]}$

The effect of molecular weight has been reported as the crucial factor for the fucoidan bioactivity. Previous in vitro studies showed that lower molecular weight fucoidan significantly increased the anticancer activity of fucoidan. ${ }^{[23,36,39]}$ Furthermore, it has been described that even with higher amounts of sulfation, molecular weight plays a more decisive role. ${ }^{[2]}$ Among the fucoidans studied in the present work, FE 1 has the highest molecular weight when compared with FE 2 and FE 3, but the latter are the ones presenting toxicity to breast cancer cells. Molecular weight is known to be associated with cell internalization, among other factors, from which we hypothesized that when comparing FE 2 with FE 1, only FE 2 (lower molecular weight) would be internalized by cancer cells and exert its antitumor action. ${ }^{[40,41]}$ However, as illustrated in Figure 5, no differences were observed in the cellular internalization of FE 1 and FE 2. Thus, these results do not give any conclusions regarding the relationship between cellular internalization and the molecular weight for the studied system.

It has been described that hydrolyzed fucoidan exhibited a higher percentage of anticancer activity. ${ }^{[24,38]}$ In 
particular, hydrolyzed fucoidan under mild conditions (in boiling water with $\mathrm{HCl}$ ) showed higher antitumor activity whereas hydrolyzed fucoidan generated under harsh conditions (microwave) slightly enhanced the anticancer effects. ${ }^{[24]}$ In this sense, FE 1 was hydrolyzed by acidic reaction to assess if the resulting fucoidan, FE 1*, with lower molecular weight, would present toxicity over cancer cells. However, as seen in Figure 6 , this lower molecular weight extract did not present toxicity to normal and cancer cells. It has been described that acidic hydrolysis can reduce also sulfate content and depolymerization could change monosaccharides ratio, as, e.g., decreasing the level of uronic acids. ${ }^{[39,42]}$ Besides, by comparing FE $1^{*}$ and FE 3 it is possible to conclude that despite having similar molecular weight the two extracts present significant differences in their bioactivity response. These results suggest that the antitumor behavior may be related with other factors and not directly associated with fucoidans' molecular weight.

The studied fucoidan extracts have a total percentage of carbohydrates between 50.5 and 52.5 and of sulfates between 28.0 and 29.3, which means that the total amount of polysaccharides present in the samples varies between $78.5 \%$ and $81.8 \%$. These results confirm that fucose and sulfates are the main components of fucoidan from $F$. vesiculosus, as described elsewhere. ${ }^{[25,43]}$ The uronic acids content has been determined in fucoidan composition, although we need to be cautious in assuming that the full uronic acid measured is contained within the fucoidan polymers, as has been described elsewhere. ${ }^{[44]}$ The carbohydrates composition did not indicate any clear structure-activity relationship (SAR).

Higher sulfation is related with greater molecular bioactivity and thus researchers have produced over-sulfated fucoidans to enhance its biological properties. ${ }^{[29]}$ It has been suggested that over-sulfation causes higher negative charge in the molecule, which facilitate formation of fucoidan-protein complexes involved in cell proliferation. ${ }^{[31]}$ Sulfate mass quantification of the three fucoidan extracts did not present significant variation. Despite these results, sulfates can still play a role in the antitumor activity, since the same sulfation degree can correspond to different sulfates position, i.e., sulfation distribution along fucoidan backbone, presenting distinct biological response. Thus, both sulfates position and polymer branching were assessed to better understand the role of the chemical structure on the exhibited biological activity. The FE 2 was the polysaccharide with higher percentage of fully branched chains (together in 3-O and 4-O-Fuc) and, as a consequence, it is a more branched structure than the other ones. Also, as all hydroxyl groups are linked, they could not have sulfates in these residues. The sulfates occur mainly in 2-O-Fuc. In comparison with
FE 2, FE 1 had higher sulfation in 4-O-Fuc and 3-O-Fuc while FE 3 had higher sulfation in 4-O-Fuc. Consequently, the sulfates position is different for the three fucoidans. It is possible that these structural differences may influence their cytotoxicity response, particularly regarding the breast cancer cell lines tested.

It is thus shown here that the antitumor behavior is not ubiquitous, as could be inferred from the published reports, but dependent on their chemical structure, being also important to highlight that the same fucoidan extract can present different effects over different types of cells and cancers. ${ }^{[15]}$

As referred before, the source (original species) and extraction method are two factors that may affect fucoidan intrinsic properties and that are commonly associated with fucoidans' bioactivity. Fucoidan preparations isolated from different sources have shown differential anticancer effects in vivo due to corresponding structural properties. ${ }^{[22]}$ Since the source of fucoidan is the same for the three extracts (i.e., F. vesiculosus), the extraction method may be the factor influencing fucoidan intrinsic properties and thus the different antitumor behavior. Even from the same company, we have different batches that can present different behaviors. The preservation of the fucoidan molecules' structural integrity essentially depends on the extraction methodology which has a crucial, but partly ignored, significance for obtaining the relevant structural features required for specific biological activities and for elucidating structure-function relations. ${ }^{[14]}$

To be suited to a regulated product, fucoidan extracts must be defined and reproducible. Sustainable, clean, and regulated harvesting, or culturing of a single type of seaweed are required. In order to meet therapeutic regulatory requirements, common extraction methods and distributions of fully characterized fucoidans need to be taken into consideration. This is particularly relevant when trying to take a product from a preclinical concept to clinical trials. The development and use of such consistent extraction procedures would also help in achieving a better understanding of structure-activity relationship of fucoidan extracts.

\section{Conclusions}

Despite the promising results about the anticancer effects of fucoidan, some variability impedes its utilization in the clinic. Specifically, contradictory experimental results influenced by endogenous and exogenous factors in fucoidan usage are the main barriers. It is also important to have in mind that the ultimate goal of an effective cancer therapy is to damage cancer cells without negatively affect the surrounding healthy environment. This distinctive action mode was only observed with the 
FE 2 being important to characterize the physicochemical properties of the different extracts. The present results allow to infer that the molecular weight, monosaccharides composition, and content of sulfates could not be related with the cytotoxicity of FE 1, FE 2, and FE 3 extracts. From our results, we can conclude that the branching degree of the fucoidans may be the most obvious cause of the different biological behavior of the three extracts.

In this sense, more focus should be direct to the optimization and standardization of the extraction and purification processes to obtain consistent protocols that account for the biodiversity of fucoidan extracts, from different seaweeds, and to retain the structural features of significance for specific bioactivity of fucoidan extracts. Furthermore, the determination and clarification of the structural characteristics responsible for antitumor activities of fucoidan will be essential for its potential as a marine-origin drug.

\section{Experimental Section}

\subsection{Materials}

FE 1 was purchased from Marinova, whereas Fucoidan Extract 2 (FE 2 - batch SLBC6348V) and Fucoidan Extract 3 (FE 3 - batch 081M7672V), were purchased from Sigma-Aldrich, all used as received. The human vascular endothelial growth factor ELISA kit was purchased from Peprotech (Rochy Hill, NJ, USA) and kept at $4{ }^{\circ} \mathrm{C}$ until used. Phalloidin-Tetramethylrhodamine B isothiocyanate (Texas Red - Phalloidin), DTAF were both purchased from Sigma. 4,6-Diamidino-2-phenyindole, dilactate (DAPI) was purchased from Biotium (Hayward, CA, USA).

\subsection{Biological Assays}

\subsubsection{Cell Expansion}

Human fibroblasts (MRC-5 cell line) and pulmonary microvascular endothelial cells (HPMEC-ST1.6R cell line) were used as noncancer cells. Fibroblast cells were cultured in D-MEM low glucose medium (Sigma-Aldrich) supplemented with 10\% FBS (Alfagene) and Pen/Strep (100 U/100 $\mathrm{g} \mathrm{mL}^{-1}$; Life Technologies). Fibroblasts were used at passages 14-16. Endothelial cells were cultured in M199 medium (Sigma-Aldrich) supplemented with $20 \%$ FBS (Alfagene), $2 \times 10^{-3}$ M Glutamax (Life Technologies), Pen/Strep (100 U/100 $\mathrm{g} \mathrm{mL}^{-1}$; Life Technologies), endothelial cell growth supplement (ECGS $-25 \mu \mathrm{g} \mathrm{mL}^{-1}$; Becton Dickinson). Endothelial cells were used at passages 38-40.

Human breast adenocarcinoma cells (MCF-7 and MDA-MB-231 cell lines) were used to assess the effect of different fucoidan's concentrations over these cancer cells models. Both cell lines were cultured in D-MEM high glucose medium (Sigma-Aldrich) supplemented with 10\% Fetal Bovine Serum (FBS) (Alfagene), Pen/Strep (100 U/100 $\mathrm{g} \mathrm{mL}^{-1}$; Life Technologies) and 1\% MEM sodium pyruvate solution $100 \times 10^{-3} \mathrm{M}$ (Alfagene). The MCF-7 cell line was used at passages $16-18$, whereas the MDA-MB-231 cell line was used at passages $42-44$.
The four types of cells were incubated at $37{ }^{\circ} \mathrm{C}$ in a humidified $5 \% \mathrm{CO}_{2}$ atmosphere. Media were exchanged every 2-3 days until cells reached a $90 \%$ confluence.

\subsubsection{Cell Culture}

Noncancer and cancer cells were harvested and 15000 cells were cultured in 24 well-plates. The cells were left to adhere for $4 \mathrm{~h}$ and, after that, fucoidan extracts were added to adherent cells. Fucoidan extracts were dissolved in the culture medium at different concentrations: for FE 1 the concentrations tested were $0.1,0.5,1,2,3,4$, and $5 \mathrm{mg} \mathrm{mL}^{-1}$, whereas for FE 2 and FE 3 the concentrations were $0.1,0.2,0.3,0.4$, and $0.5 \mathrm{mg} \mathrm{mL}^{-1}$. For all the assays a positive control was performed (no fucoidan in the culture medium). Each experimental condition was tested in triplicate and two independent assays were performed for each type of cells and fucoidan extracts.

\subsubsection{Cell Viability}

The metabolic activity of noncancer and cancer cells, cultured at different fucoidan extracts' concentrations and time points, was determined by the MTS assay (CellTiter 96 AOueous One Solution, Promega). The MTS assay is a colorimetric method commonly used for cytotoxicity assays or for determining the number of viable cells in proliferation. Basically, the quantity of formazan product is directly proportional to the number of living cells in culture. ${ }^{[45]}$ At days 1,2 , and 3, the culture medium was removed and the testing conditions were rinsed with sterile Phosphate-Buffered Saline (PBS). A mixture of culture medium (without FBS and phenol red) and MTS reagent (5:1 ratio) was added to each well and left to incubate for $3 \mathrm{~h}$, at $37^{\circ} \mathrm{C}$, in a humidified $5 \% \mathrm{CO}_{2}$ atmosphere. Thereafter, the absorbance of the MTS reaction medium from each sample was read in triplicate at $490 \mathrm{~nm}$ in a microplate reader (Synergy HT, Bio-TEK). All experiments were performed in triplicate.

\subsubsection{DTAF-Labeled Fucoidan and Morphological Observation}

DTAF-labeled fucoidan was prepared as described elsewhere. ${ }^{[46,47]}$ Briefly, DTAF was reconstituted in methanol and kept at $4{ }^{\circ} \mathrm{C}$ until further use. A $0.2 \mathrm{mg} \mathrm{mL}^{-1}$ solution of FE 1 and FE 2 was left to stir with DTAF for $3 \mathrm{~h}\left(20 \mu \mathrm{g} \mathrm{mL}^{-1}\right)$. The procedure described in Sections 5.2.2 and 5.2.3 were followed, but was added DTAFlabeled FE 1 and FE 2 instead of the pure FE. At days 1, 2, and 3, samples were washed with PBS, fixed for 30 min with $10 \%$ formalin, washed again with PBS and kept in PBS at $4^{\circ} \mathrm{C}$.

To evaluate whether and where fucoidan has been internalized by the different cell types, the nucleus and cytoskeleton of those cells were also fluorescent labeled. First, a blocking step was performed with $3 \%$ Bovine Serum Albumin (BSA) in PBS for $30 \mathrm{~min}$. Then, the BSA solution was removed and cells were washed with PBS. After that, Phalloidin-Tetramethylrhodamine B isothiocyanate (1:200 in PBS) was added and left incubating for $45 \mathrm{~min}$. Another washing step was performed and the same samples were incubated with 4,6-Diamidino-2-phenyindole, dilactate (1:1000 in PBS) for 15 min. Cell were washed with PBS and observed in a transmitted and reflected light microscope with Apotome 2 (Axio Imager Z1m, Zeiss). 


\subsection{Fucoidan Characterization}

\subsubsection{Molecular Weight Determination by Gel Permeation Chromatography}

GPC measurements were performed with a Malvern Viscotek TDA 305 with refractometer, right angle light scattering and viscometer detectors on a set of four columns: precolumn Suprema $5 \mu \mathrm{m} 8 \times 50 \mathrm{~S} / \mathrm{N} 3111265$, Suprema $30 \AA 5 \mu \mathrm{m} 8 \times 300 \mathrm{~S} / \mathrm{N}$ 3112751, Suprema $1000 \AA 5 \mu \mathrm{m} 8 \times 300 \mathrm{~S} / \mathrm{N} 3112851 \mathrm{PL}$, and Aquagel-OH MIXED $8 \mu \mathrm{m} 7.5 \times 300$ S/N 8M-AOHMIX-46-51, with refractive index detection (RI-Detector 8110, Bischoff). The system was kept at $30{ }^{\circ} \mathrm{C}$ using $0.1 \mathrm{M} \mathrm{NaN}_{3}, 0.01 \mathrm{M} \mathrm{NaH}_{2} \mathrm{PO}_{4}$

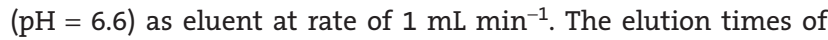
the RI detector signal were calibrated with a commercial polysaccharide set from Varian that contains 10 Pullulans with narrow polydispersity and $\mathrm{Mp}$ (molecular mass at the peak maximum) ranging from $180 \mathrm{Da}$ to $708 \mathrm{kDa}$.

\subsubsection{Depolymerization of Fucoidan Extract FE1 by Acid Hydrolysis}

FE 1 was hydrolyzed to obtain lower molecular weight fucoidan, following a procedure described previously. ${ }^{[38]}$ Briefly, partially hydrolyzed fucoidan was obtained by hydrolyzing FE 1 (20 mg) with $1 \mathrm{~mL}$ of $0.01 \mathrm{M} \mathrm{HCl}$ at $100{ }^{\circ} \mathrm{C}$ for $10 \mathrm{~min}$, followed by neutralization with $1 \mathrm{~mL}$ of $0.01 \mathrm{~m} \mathrm{NaOH}$. The resulting hydrolyzed fucoidan FE1* was analyzed by GPC. A control was performed by dissolving $\mathrm{FE} 1(20 \mathrm{mg})$ in $1 \mathrm{~mL}$ of $0.01 \mathrm{M} \mathrm{HCl}$ without heat treatment, followed by neutralization with $1 \mathrm{~mL}$ of $0.01 \mathrm{M} \mathrm{NaOH}$. The procedures described in Sections 5.2.2 and 5.2.3 were followed, but, instead of FE 1, hydrolyzed fucoidan was added at different concentrations $\left(0.2,0.5\right.$, and $\left.1 \mathrm{mg} \mathrm{mL}^{-1}\right)$. A positive control with untreated cells and controls with $\mathrm{HCl}$ and $\mathrm{NaOH}$ without fucoidan were also performed.

\subsubsection{Carbohydrates Composition: Determination of Neutral and Acidic Monosaccharides}

Neutral monosaccharides were determined as alditol acetates as described elsewhere. ${ }^{[48]}$ Briefly a prehydrolysis of fucoidans was performed, with $72 \%$ sulfuric acid for $3 \mathrm{~h}$ at room temperature (RT). Afterward, the fucoidan extracts were submitted to a hydrolysis with sulfuric acid $1 \mathrm{~m}$ at $100{ }^{\circ} \mathrm{C}$ for $2.5 \mathrm{~h}$. 2-Deoxyglucose was used as an internal standard. Monosaccharides were reduced with sodium borohydride and acetylated by acetic anhydride using methylimidazole as a catalyst. The formed alditol acetate derivatives were analyzed by gas chromatography (GC) with a $30 \mathrm{~m}$ column DB-225 (J\&W Scientific, Folsom, CA, USA), internal diameter, and film thickness of 0.25 and $0.15 \mathrm{~mm}$, respectively, and using a flame ionization detector (Perkin Elmer, Clarus 400). The hydrolysis of all samples was performed in duplicate and each one was injected twice. A third analysis was done for the few samples with higher variability. Uronic acids were quantified by a modification of the 3-phenylphenol colorimetric method. ${ }^{[48]}$ Samples were prepared by hydrolysis with $72 \%$ sulfuric acid for $3 \mathrm{~h}$ at RT followed by $1 \mathrm{~h}$ in sulfuric acid $1 \mathrm{M}$ at $100{ }^{\circ} \mathrm{C}$. A calibration curve was made with D-galacturonic acid. The hydrolysis and analysis of the samples was done in triplicate.

\subsubsection{NMR Spectroscopy}

NMR experiments were acquired on a Bruker AVANCE 400 spectrometer using $\mathrm{D}_{2} \mathrm{O}$ as solvent. The residual HOD signal was used as reference for the chemical shifts that are reported in ppm. Mnova Software 9.0 (Mestrelab Research) was used for spectral processing. Sulfation position and branching was qualitatively analyzed based on the chemical shifts described previously. ${ }^{[26,27]}$

\subsubsection{Sulfation Degree: Ester Sulfate Determination}

The content of ester sulfates in the fucoidan extracts was determined by the turbidimetric method proposed by Dodgson and Price. ${ }^{[49,50]}$ The fucoidan extracts were accurately weighed (usually 2-4 mg) and dissolved in the respective amount of $\mathrm{N}$-hydrochloric acid $1 \mathrm{M}$. The mixture was submitted to a hydrolysis at $105-110^{\circ} \mathrm{C}$ for $5 \mathrm{~h}$. A portion $(0.2 \mathrm{~mL})$ was transferred to a tube containing $3.8 \mathrm{~mL}$ of $3 \%(\mathrm{w} / \mathrm{v})$ trichloroacetic acid. Barium chloride-gelatin reagent $(1 \mathrm{~mL})$ was added and, after mixing, the whole was kept at RT for 15-20 min. The barium chloridegelatin reagent was previously prepared by mixing gelatin ( $1 \mathrm{~g}$ ) with $200 \mathrm{~mL}$ of hot water $\left(60-70^{\circ} \mathrm{C}\right)$ and was allowed to stand at $4{ }^{\circ} \mathrm{C}$ overnight. Barium chloride ( $1 \mathrm{~g}$ ) was dissolved in the semigelatinous fluid and the resultant cloudy solution was allowed to stand for 2-3 $\mathrm{h}$ before use. The solution was then analyzed at $360 \mathrm{~nm}$ (Jenway $6405 \mathrm{UV} / \mathrm{Vis}$ ) against reagent blank containing distilled water instead of sample.

A second $0.2 \mathrm{~mL}$ portion of the hydrolysate was mixed with $3.8 \mathrm{~mL}$ of trichloroacetic acid, as described above, and with $1 \mathrm{~mL}$ of gelatin solution (i.e., containing no barium chloride). The extinction of this "control" solution was then measured at $360 \mathrm{~nm}$ against a reagent blank consisting on distilled water instead of sample and $1 \mathrm{~mL}$ of gelatin solution. The concentration of sulfate esters was determined by building a $\mathrm{K}_{2} \mathrm{SO}_{4}$ calibration curve, containing between 20 and $200 \mu \mathrm{g}$ of $\mathrm{SO}_{4}{ }^{2-}$ ion.

\subsubsection{Desulfation}

For polysaccharide desulfation, $10 \mathrm{mg}$ were dissolved in $1.8 \mathrm{~mL}$ of dried dimethyl sulfoxide. Then, $0.1 \mathrm{~mL}$ pyridine was added, followed by $13 \mathrm{mg}$ of pyromellitic acid, $12 \mathrm{mg}$ of $\mathrm{NaF}$, and $0.2 \mathrm{~mL}$ of pyridine. The mixture was stirred at $120^{\circ} \mathrm{C}$ for $3 \mathrm{~h}$, cooled and poured into $1 \mathrm{~mL}$ of $3 \%$ of $\mathrm{NaHCO}_{3}$ aqueous solution. The solution containing the desulfated polysaccharide was dialysed and freeze-dried. The procedure was repeated in order to guarantee the complete desulfation. Afterward, the desulfated polysaccharide was submitted to methylation analysis. ${ }^{[51,52]}$

\subsubsection{Methylation Analysis}

Glycosidic-substitution analysis was determined by gas chromatography-quadrupole mass spectrometry (GC-qMS) of the partially methylated alditol acetates based on Ciucanu and Kerek ${ }^{[53]}$ and Coelho et al. ${ }^{[54]}$ The native and desulfated samples (1-2 mg) were dissolved in $1 \mathrm{~mL}$ of anhydrous dimethylsulfoxide, and then powdered $\mathrm{NaOH}$ (40 mg) were added under an argon atmosphere. The samples were methylated with $\mathrm{CH}_{3} \mathrm{I}(80 \mu \mathrm{L})$ during 20 min with stirring, following by a second and third addition of $80 \mu \mathrm{L}$ $\mathrm{CH}_{3} \mathrm{I}$ and stirring for another $20 \mathrm{~min} . \mathrm{CHCl}_{3} / \mathrm{MeOH}(1: 1, \mathrm{v} / \mathrm{v}, 3 \mathrm{~mL})$ 
was added, and the solution was dialyzed (membrane with a pore diameter of $12-14 \mathrm{kDa}$ ) against $50 \% \mathrm{EtOH}$. The dialysate was evaporated to dryness and the material was remethylated using the same procedure. The remethylated material was hydrolyzed with $2 \mathrm{M}$ TFA $(1 \mathrm{~mL})$ at $120^{\circ} \mathrm{C}$ for $1 \mathrm{~h}$, and then reduced and acetylated as previously described for neutral sugar analysis (using $\mathrm{NaBD}_{4}$ instead of $\mathrm{NaBH}_{4}$ ). The partially methylated alditol acetates were separated and analyzed by GC-qMS (GC-2010 Plus, Shimadzu). The GC was equipped with a DB-1 (J\&W Scientific, Folsom, CA, USA) capillary column (30 m length, $0.25 \mathrm{~mm}$ of internal diameter, and $0.10 \mu \mathrm{m}$ of film thickness). The samples were injected in "split" mode with the injector temperature at $250{ }^{\circ} \mathrm{C}$. The temperature program used was as follows: (1) an initial temperature of $80^{\circ} \mathrm{C}$; (2) an increase of $7.5^{\circ} \mathrm{C} \mathrm{min}-1$ until $140{ }^{\circ} \mathrm{C}$ and a hold time of $5 \mathrm{~min}$; (3) an increase of $0.2{ }^{\circ} \mathrm{C} \mathrm{min}-1$ until $143.2{ }^{\circ} \mathrm{C}$; (4) an increase of $12{ }^{\circ} \mathrm{C} \mathrm{min}-1$ until $200{ }^{\circ} \mathrm{C}$; (5) an increase of $50{ }^{\circ} \mathrm{C} \mathrm{min}-1$ until $250{ }^{\circ} \mathrm{C}$ and a hold time of $5 \mathrm{~min}$. The helium carrier gas had a total flow rate of $8.5 \mathrm{~mL} \mathrm{~min}^{-1}$. The GC was connected to GCMS-OP 2010 Ultra Shimadzu mass quadrupole selective detector operating with an electron impact mode at $70 \mathrm{eV}$ and scanning the range $\mathrm{m} / \mathrm{z} 50-700$ in a $1 \mathrm{~s}$ cycle in a full scan mode acquisition.

\subsection{Statistical Analysis}

Statistical analysis was performed using Graph Pad Prism Software. Differences between the different conditions of the cellular assays were analyzed using nonparametric test (Kruskal-Wallis test) and a $p<0.05$ was considered significant. Data are presented as mean \pm standard deviations.

Acknowledgements: The authors would like to thank the funding from projects 0687_NOVOMAR_1_P, cofunded by INTERREG 2007-2013/POCTEP, CarbPol $\bar{u}$ Algae (EXPL/ MAR-BIO/0165/2013), and IF/00376/2014/CP1212/CT0015, funded by the Portuguese Foundation for Science and Technology, FCT, and ComplexiTE (ERC-2012-ADG 20120216321266), funded by the European Research Council under the European Union's Seventh Framework Programme for Research and Development. The authors would also like to thank FCT, Portugal, for the scholarship of A.S.F. (SFRH/BD/102471/2014), fellowship of C.N. (SFRH/BPD/100627/2014), Investigator grants of A.M. (IF/00376/2014), R.N.-C. (IF/00373/2014), and I.P. (IF/00032/2013) and the financial support to CICECO- Aveiro Institute of Materials (POCI-01-0145-FEDER-007679, FCT UID/ CTM/50011/2013) and OOPNA (UID/OUI/00062/2013), through national founds and cofinanced by the FEDER, within the PT2020 Partnership Agreement.

Received: August 8, 2016; Revised: November 16, 2016; Published online: ; DOI: 10.1002/mabi.201600340

Keywords: antitumor activity; fucoidan; polymer branching; structure-activity relationship; sulfation

[1] G. M. Cooper, The Cell - A Molecular Approach, Sinauer Associates, Sunderland, MA 2000.

[2] K. Sak, Chemother. Res. Pract. 2012, 2012, 282570.
[3] A. Gennari, M. D'amico, D. Corradengo, Ther. Adv. Med. Oncol. 2011, 3, 229.

[4] C. DeSantis, J. Ma, L. Bryan, A. Jemal, CA. Cancer J. Clin. 2014, $64,52$.

[5] National Collaborating Centre for Cancer, U. National Collaborating Centre for Cancer, UK 2009.

[6] M. M. Gottesman, Annu. Rev. Med. 2002, 53, 615.

[7] H.-Y. Hsu, T.-Y. Lin, Y.-C. Wu, S.-M. Tsao, P.-A. Hwang, Y.-W. Shih, J. Hsu, Oncotarget 2014, 5, 7870.

[8] F. Atashrazm, R. M. Lowenthal, G. M. Woods, A. F. Holloway, J. L. Dickinson, Mar. Drugs 2015, 13, 2327.

[9] T. H. Silva, a. Alves; B. M. Ferreira, J. M. Oliveira, L. L. Reys, R. J. F. Ferreira, R. a Sousa; S. S. Silva, J. F. Mano, R. L. Reis, Int. Mater. Rev. 2012, 57, 276.

[10] J. H. Fitton, D. N. Stringer, S. S. Karpiniec, Mar. Drugs 2015, 13, 5920.

[11] L. Yang, P. Wang, H. Wang, O. Li, H. Teng, Z. Liu, W. Yang, L. Hou, X. Zou, Mar. Drugs 2013, 11, 1961.

[12] N. Li, O. Zhang, J. Song, Food Chem. Toxicol. 2005, 43, 421.

[13] B. Li, F. Lu, X. Wei, R. Zhao, Molecules 2008, 13, 1671.

[14] M. T. Ale, J. D. Mikkelsen, A. S. Meyer, Mar. Drugs 2011, 9, 2106.

[15] G. Moussavou, D. H. Kwak, B. W. Obiang-Obonou, C. A. O. Maranguy, S.-D. Dinzouna-Boutamba, D. H. Lee, O. G. M. Pissibanganga, K. Ko, J. I. Seo, Y. K. Choo, Mar. Drugs 2014, 12, 4898.

[16] M. T. Ale, H. Maruyama, H. Tamauchi, J. D. Mikkelsen, A. S. Meyer, Int. J. Biol. Macromol. 2011, 49, 331.

[17] H.-J. Boo, J.-H. Hyun, S.-C. Kim, J.-I. Kang, M.-K. Kim, S.-Y. Kim, H. Cho, E.-S. Yoo, H.-K. Kang, Phytother. Res. 2011, 25, 1082.

[18] H.-J. Boo, J.-Y. Hong, S.-C. Kim, J.-I. Kang, M.-K. Kim, E.-J. Kim, J.-W. Hyun, Y.-S. Koh, E.-S. Yoo, J.-M. Kwon, H.-K. Kang, Mar. Drugs 2013, 11, 2982.

[19] Z. Zhang, K. Teruya, T. Yoshida, H. Eto, S. Shirahata, Mar. Drugs 2013, 11, 81.

[20] H. Lee, J. S. Kim, E. Kim, PLoS One 2012, 7, e50624.

[21] K. Senthilkumar, P. Manivasagan, J. Venkatesan, S.-K. Kim, Int. J. Biol. Macromol. 2013, 60, 366.

[22] J.-Y. Kwak, Mar. Drugs 2014, 12, 851.

[23] A. Kasai, S. Arafuka, N. Koshiba, D. Takahashi, K. Toshima, Org. Biomol. Chem. 2015, 13, 10556.

[24] F. Atashrazm, R. Lowenthal, G. Woods, A. Holloway, J. Dickinson, Mar. Drugs 2015, 13, 2327.

[25] B. Li, F. Lu, X. Wei, R. Zhao, Molecules 2008, 13, 1671.

[26] M.-J. Clément, B. Tissot, L. Chevolot, E. Adjadj, Y. Du, P. A. Curmi, R. Daniel, Glycobiology 2010, 20, 883.

[27] M. I. Bilan, A. A. Grachev, A. S. Shashkov, N. E. Nifantiev, A. I. Usov, Carbohydr. Res. 2006, 341, 238.

[28] S. Koyanagi, N. Tanigawa, H. Nakagawa, S. Soeda, H. Shimeno, Biochem. Pharmacol. 2003, 65, 173.

[29] L. Chevolot, B. Mulloy, J. Ratiskol, A. Foucault, S. Colliec-Jouault, Carbohydr. Res. 2001, 330, 529.

[30] V. H. Pomin, P. A. S. Mourão, Glycobiology 2008, 18, 1016.

[31] S. Z. Moghadamtousi, H. Karimian, R. Khanabdali, M. Razavi, M. Firoozinia, K. Zandi, H. A. Kadir, Sci. World. J. 2014, 2014, 768323.

[32] K. Wang, L.-H. Cai, B. Lan, J. J. Fredberg, Nat. Methods 2016, $13,124$.

[33] F. R. Balkwill, M. Capasso, T. Hagemann, J. Cell Sci. 2012, 125, 5591.

[34] D. L. Holliday, V. Speirs, Breast Cancer Res. 2011, 13, 215.

[35] A. S. Levenson, V. C. Jordan, Cancer Res. 1997, 57, 3071.

[36] R. Kimura, T. Rokkaku, S. Takeda, M. Senba, N. Mori, Mar. Drugs 2013, 11, 4267. 
[37] R. V. J. Chari, Acc. Chem. Res. 2008, 41, 98.

[38] C. Yang, D. Chung, I.-S. Shin, H. Lee, J. Kim, Y. Lee, S. You, Int. J. Biol. Macromol. 2008, 43, 433.

[39] J. I. Choi, H. J. Kim, Carbohydr. Polym. 2013, 97, 358.

[40] L. Zhang, S. Bhatnagar, E. Deschenes, M. Thurber Greg, Sci. Rep. 2016, 6, 25424.

[41] M. M. Schmidt, K. D. Wittrup, Mol. Cancer Ther. 2009, 8, 2861.

[42] L.-E. Rioux, S. L. Turgeon, M. Beaulieu, Phytochemistry 2010, $71,1586$.

[43] T. Nishino, C. Nishioka, H. Ura, T. Nagumo, Carbohydr. Res. 1994, 255, 213.

[44] M. Nagaoka, H. Shibata, I. Kimura-Takagi, S. Hashimoto, K. Kimura, T. Makino, R. Aiyama, S. Ueyama, T. Yokokura, Glycoconj. J. 1999, 16, 19.

[45] T. M. Buttke, J. A. McCubrey, T. C. Owen, J. Immunol. Methods 1993, 157, 233.
[46] S. Prigent-Richard, M. Cansell, J. Vassy, A. Viron, E. Puvion, J. Jozefonvicz, D. Letourneur, J. Biomed. Mater. Res. 1998, 40, 275.

[47] M. Ellouali, C. Boisson-Vidal, P. Durand, J. Jozefonvicz, Anticancer Res. 1993, 13, 2011.

[48] C. Nunes, L. Silva, A. P. Fernandes, R. P. F. Guiné, M. R. M. Domingues, M. A. Coimbra, Carbohydr. Polym. 2012, 87,620 .

[49] K. S. Dodgson, Biochem. J. 1961, 78, 312.

[50] K. S. Dodgson, R. G. Price, Biochem. J. 1962, 84, 106.

[51] I. J. Miller, J. W. Blunt, Carbohydr. Res. 1998, 309, 39.

[52] S. Geresh, S. M. Arad, O. Levy-Ontman, W. Zhang, Y. Tekoah, R. Glaser, Carbohydr. Res. 2009, 344, 343.

[53] I. Ciucanu, F. Kerek, Carbohydr. Res. 1984, 131, 209.

[54] S. Vincenzi, A. Crapisi, A. Curioni, Food Hydrocoll. 2014, 34, 202. 